\title{
A STUDY OF PROPORTION OF DISABILITY AND ITS DETERMINANTS AMONG LEPROSY PATIENTS
}

Kavya Shree K. L1, Raghu M. T22, Aravind Karinagannanavar³, Manjunatha S4

\section{HOW TO CITE THIS ARTICLE:}

Kavya Shree K. L, Raghu M. T, Aravind Karinagannanavar, Manjunatha S. "A Study of Proportion of Disability and its Determinants among Leprosy Patients". Journal of Evolution of Medical and Dental Sciences 2015; Vol. 4, Issue 62, August 03; Page: 10742-10746, DOI: 10.14260/jemds/2015/1551

ABSTRACT: BACKGROUND: Widespread implementation of MDT has clearly been extremely successful in curing and reducing the prevalence of leprosy throughout the world including India. However, social stigma remains a major obstacle to self-reporting and early treatment. OBJECTIVES: 1) To study the proportion of disabilities as per the WHO definition in newly detected leprosy patients. 2) To know the determinants of disabilities in newly detected leprosy patients. METHODOLOGY: A cross sectional study was conducted in urban leprosy center Hubli. Data was collected by 500 leprosy patients who had registered between December 2008 to 2013. Demographic profile of the patients, presence and type of disability and determinants of disability were collected from the register maintained in urban leprosy center Hubli. RESULTS: 100 deformity cases $(20 \%)$ were found among 500 cases. The majority of deformity cases were in the age group of 20 -30 years (24\%), 78\% were male patients. $74 \%$ had grade- 2 deformity, with claw hand in $37 \%$, foot drop in 9\%, trophic ulcer in 27\%, 1\% ocular deformity and 26\% grade 1 deformity seen (loss of sensation). Out of 100 deformity cases, borderline leprosy cases were 80(80\%), tuberculoid type $1(1 \%)$, lepromatous type were $3(3 \%), 13(13 \%)$ were pure neuritic type, $2(2 \%)$ were indeterminate type, $1(1 \%)$ histoid type. New cases (Not on the treatment) with deformity were $70 \%$, old cases (On treatment) with deformity were 30\%. CONCLUSION: Proportion of Disabilities among leprosy patients were 20\%. Disabilities were more common among males, borderline leprosy cases and new cases.

KEYWORDS: Leprosy, Deformities, Determinants.

INTRODUCTION: Widespread implementation of MDT has clearly been extremely successful in curing and reducing the prevalence of leprosy throughout the world including India. As on $1^{\text {st }}$ April'09 the prevalence rate of leprosy in India was 0.72/10000. In recent years under leprosy control programme more attention has been given to prevention of disability.(1,2) Among communicable diseases, leprosy remains a leading cause of peripheral neuropathy and disability in the world, despite extensive efforts to reduce the disease burden. In 2009, WHO launched the Enhanced Global strategy for further reducing the disease burden due to leprosy for 2011-15, under which the target was to reduce number of new cases of leprosy with grade-2 disability (G2D) per 100000 population by at least 35\% between the end of 2010 and the end of 2015 instead of leprosy prevalence. In 1995-2010 G2D has decreased every 5 year by $12.7 \%$ in Brazil, $7.7 \%$ in China, $53.7 \%$ in India and 35.9\% in Thailand (Endemic countries in the world at present).(3)

However, social stigma remains a major obstacle to self-reporting and early treatment. Patients are compelled to hide their condition and avoid diagnosis, allowing a completely curable disease to worsen to the point of disfigurement. This study was conducted to explore various epidemiological factors of deformities associated with leprosy. 


\section{ORIGINAL ARTICLE}

\section{OBJECTIVES:}

1. To study the proportion of disabilities as per the WHO definition in newly detected leprosy patients.

2. To know the determinants of disabilities in newly detected leprosy patients.

\section{METHODOLOGY:}

Type of study: Observational study.

Study Design: A cross sectional study.

Study Setting \& Study Period: Data was collected from the registered maintained in the Urban Leprosy Centre Hubli in past 5 years, December 2008 to 2013.

Sample Size: 500 .

Sampling Unit: Patient registered in Urban Leprosy Centre Hubli between December 2008 to 2013.

Sampling Frame: Patients registered in Urban Leprosy Centre Hubli between December 2008 to 2013.

Sampling Technique: Census Method Ethical clearance certificate for the study was obtained from the Institutional Ethical Committee.

Method of Data collection: Data was collected with pre designed semi structured questionnaire. Demographic profile of the patients, presence and type of disability and determinants of disability were collected from the register maintained in urban leprosy centre Hubli. Disabilities of hands, feet, eyes \&face were recorded into Grade 1-3 according to WHO grading of leprosy.(4) The data were analyzed using the Ridley-Jopling classification of leprosy i.e. tuberculoid, borderline (BT, $\mathrm{BB}, \mathrm{BL})$ \& lepromatous leprosy.

\section{WHO disability grading 1998.(5)}

\section{Hands and feet:}

- Grade '0' No anesthesia, no visible deformity or damage.

- Grade ' 1 ' Anesthesia present, but no visible deformity or damage.

- Grade '2' visible deformity or damage present.

Eyes:

- Grade '0' No eye problem due to leprosy, no evidence of visual loss.

- Grade ' 1 ' Eye problem due to leprosy present, but vision not severely affected as a result of this (vision 6/60 or better; can count fingers at 6 meters distance, corneal sensation testingoptional).

- Grade '2' Severe visual impairment (Vision: worse than 6/60: inability to count fingers at 6 meters distance), also includes lagopthalmus, iridocyclitis and corneal opacities.

Statistical Tools: The data will be entered in Excel and analysed using Epi-info software version 3.4.3. Statistical tests like mean and proportion was applied. 
RESULTS: Five hundred leprosy cases were included in the study, 100 deformity cases (20\%) were found. The majority of deformity cases were in the age group of $20-30$ years (24\%), 78\% were male patients, females were $22 \%$. Among $20 \%$ deformity cases most of the patients, $74 \%$ had grade- 2 deformity, with claw hand in $37 \%$, foot drop in $9 \%$, trophic ulcer in $27 \%, 1 \%$ ocular deformity.

(Corneal erosion) and $26 \%$ grade 1 deformity seen (loss of sensation).

Out of 100 deformity cases, borderline leprosy cases were $80(80 \%)$, tuberculoid type 1(1\%), lepromatous type were 3(3\%), 13 (13\%) were pure neuritic type, 2(2\%) were indeterminate type, 1 (1\%) histoid type. New cases (not on the treatment) with deformity were $70 \%$, old cases (on treatment) with deformity were $30 \%$.

In our study, 36\% (36 patients out of 100 deformity cases) had reactions at the time presentation, in that type 1 reactions were predominant-72\% (26 type- 1 reaction cases out of total 36 reaction cases) and type 2 reactions were $28 \%$ ( 8 type- 2 reaction cases out of 36 reaction cases).

DISCUSSION: At the beginning of this new millennium we have been able to reach the last mile in the race to eliminate leprosy in most part of the world including India. The nature of leprosy problem is this shifting from simply providing anti-leprosy treatment to the affected persons to dealing with the consequences of leprosy especially prevention of disability in leprosy indicates some lacunae in the leprosy control. At the national level to asses programme effectiveness only grade- 2 disability record is maintained but for prevention of disability grade- 1 assessment is more important. Because, before visible deformity (Grade-2) occurs, nerve function impairment definitely occurs (Sensory, motor or both) i.e. those patients with grade- 2 must have passed through the stage of grade-1. Therefore while examining any leprosy case after examination of skin lesions, thorough neurological examination of peripheral nerves is essential. For this, assessment of sensory NFI, motor NFI are needed along with nerve palpitation for thickening, tenderness, reaction for detection of grade- 1 disability. This will enhance the focus on reaching the target of world health organization 2011-2012 global leprosy strategy to reduce the prevalence of grade-2.[3]

A study in south India by Mahajan and others found lower proportion of neuritic leprosy 4.6\%.[6], study in Nepal by van Brakel showed nearly $8.7 \% .{ }^{[7]}$ and Sarkar et all showed $9.4 \%$ but in our study compared to all other studies slightly higher 13\% of pure neuritic leprosy going for deformity. Males suffered more than their female counterparts, which may be due to their more exposure to outdoor activities making them more vulnerable to different injuries.[8]

Health care providers, unless remember leprosy as one of the causes of peripheral neuropathy, especially in highly endemic areas it is quite likely that these pure neuritic leprosy patients are often missed. Finally when they are diagnosed as having leprosy, it is too late. This delay in diagnosis pushes them to bear the brunt of disability due to leprosy, eyes, hands and feet are the commonly affected areas of impairment even in advanced stages. After diagnosis if we can properly educate these patients to search for grade-1 disability. After diagnosis if we can properly educate these patients for self-care like not to walk bare foot, daily inspection of hands/feet for any blisters, red care, change in occupation, etc. any visible deformity will not occur. Visible deformity (grade-2) were more in feet.

CONCLUSION: Proportion of Disabilities among leprosy patients were 20\%. Disabilities were more common among males, borderline leprosy cases and new cases. 


\section{ORIGINAL ARTICLE}

ACKNOWLEDGEMENT: Authors whole heartedly thank the staff of Urban Leprosy Centre Hubli for their kind support for data collection. Authors also thank the authors/editors/ publishers of all those articles, journals and books from where the literature for this article has been reviewed and discussed.

\section{REFERENCES:}

1. Withington SG, Joha S, Baird D, Brink M, Brink J. Assessing socio-economic factors in relation to stigmatization, impairment status and selection for rehabilitation: A 1 year cohort of new leprosy cases in North Bangladesh. Lepr Rev 2003; 74: 120-32.

2. Park K. Park's textbook of preventive and social medicine. $21^{\text {st }}$ ed. Jabalpur: M/s Bhanot publishers; 2011.p.290-303.

3. Albert CJ, Smith WC, Meima A, Wang L, Richardus JH. Potential effect of the World Health Organization's 2011-2015 global leprosy strategy on the prevalence of grade 2 disability: A trend analysis. Bull World Health Organ 2011; 89: 487-95.

4. WHO Expert Committee on Leprosy. $4^{\text {th }}$ report; Geneva. Technical Report Series No. 459. 1970. p.26-31.

5. Brandsma JW, van Brakel WH. WHO disability grading: Operational definitions. Lepr Rev 2003; 74: 300-10.

6. Mahajan PM, Jogaikar DG, Mehta JM. A study of pure neuritic leprosy -clinical experience. Indian J Lepr 1996; 68: 137-41.

7. Van Brakel WH, de Soldenhoff R, McDougall AC. The allocation of leprosy patients into Paucibacillary and Multibacillary groups for multidrug therapy, taking into account the number of body areas affected by skin and/nerve lesions. Lepr Rev 1992; 63: 231-46.

8. Jhuma Sarkar, Aparajita Dasgupta, Debashis Dutt. Disability among new leprosy patients, an issue of concern: An institution based study in an endemic district for leprosy in the state of West Bengal, India. Indian journal of dermatology, venereology, and leprology. May-June 2012/ vol. 78/ p. 328-334. 


\section{ORIGINAL ARTICLE}

\section{AUTHORS:}

1. Kavya Shree K. L.

2. Raghu M. T.

3. Aravind Karinagannanavar

4. Manjunatha S.

\section{PARTICULARS OF CONTRIBUTORS:}

1. Senior Resident, Department of Dermatology, Basaveshwar Medical College, Chitradurga, Karnataka.

2. Assistant Professor, Department of Dermatology, Basaveshwar Medical College, Chitradurga, Karnataka.

3. Assistant Professor, Department of PSM, Mysore Medical College \& Research Institute, Mysore. Karnataka.

FINANCIAL OR OTHER COMPETING INTERESTS: None
4. Tutor, Department of Dermatology, Basaveshwar Medical College, Chitradurga, Karnataka.

\section{NAME ADDRESS EMAIL ID OF THE}

\section{CORRESPONDING AUTHOR:}

Dr. Raghu M. T,

Assistant Professor,

Department of Dermatology,

Basaveshwar Medical College,

Chitradurga, Karnataka.

E-mail: raghumtaug@gmail.com

Date of Submission: 21/07/2015.

Date of Peer Review: 22/07/2015.

Date of Acceptance: 25/07/2015.

Date of Publishing: 31/07/2015. 